\title{
Simultaneous Oil Sono-Extraction And Sono- Transesterification (In Situ) Of Soybean And Sunflower Seeds For The Production Of Biodiesel
}

\section{Reyman Díaz Dolores ( $\nabla$ dolores.reyman@uam.es )}

Universidad Autonoma de Madrid https://orcid.org/0000-0003-3702-0067

\section{Quiñones Grande Almudena}

Departamento de Química Física Aplicada, C/ Francisco Tomás y Valiente, 7. Universidad Autónoma de Madrid, Ciudad Universitaria de Cantoblanco, 28049, Madrid, Spain

\section{Research}

Keywords: Sunflower, soybean, seed, ultrasound, oil extraction, in-situ transesterification and biodiesel

Posted Date: July 28th, 2020

DOI: https://doi.org/10.21203/rs.3.rs-41639/v1

License: (c) (i) This work is licensed under a Creative Commons Attribution 4.0 International License.

Read Full License 


\section{Abstract}

The cost of biodiesel production could be reduced by applying a simultaneous oil extraction and transesterification process (in situ). In situ sono-transesterification to allow direct production of biodiesel from soybean and sunflower seeds are presented in this study. All experiments were conducted using ultrasound $(20 \mathrm{kHz}, 106 \mathrm{~W})$. In the sunflower case, the results showed a higher yield of extraction (94\%) for a $1 / 5(\mathrm{~g} / \mathrm{mL})$ ratio and one minute of sonication. In the soybean case, the extraction process is less efficient, reaching only $59 \%$ of the oil contained in the seed for a soybean/n-hexane ratio of $1 / 10(\mathrm{~g} / \mathrm{mL})$ and one minute of sonication. Parameters such as the methanol/oil ratio, reaction time and catalyst concentration in the in situ sono-transesterification process of these vegetable seeds were also optimised in this study. In both cases, a percentage of conversion to biodiesel greater than $99 \%$ was achieved with just one minute of sonication.

\section{Introduction}

Increasing world population and rapid economic growth are driving up global energy demand. Petroleum is the main fuel for transport and this explains the overexploitation of this resource that is presently occurring. This overexploitation leads to environmental problems: the main cause of "global warming" is the $\mathrm{CO}_{2}$ generated in the combustion of these fuels. An alternative to fossil fuels is the use of vegetable oils, animal fats, and recycled cooking oils to produce a mixture of simple long-chain alkyl esters known as biodiesels which can be used as fuels for diesel engines. The European Directive defines biodiesel as a mixture of fatty acid methyl esters (FAME) obtained from vegetable oils and animal fats that have similarities to diesel for use as biofuel. The American Standard ASTM D6751, besides methyl, also includes ethyl, isopropyl, butyl esters, etc. Biodiesel is a feasible technological alternative to diesel with advantages: technical (decreases engine wear), environmental (reduces $\mathrm{CO}_{2}$ emissions) and socioeconomic (power in the agricultural sector). However, not all are advantages, the production of biodiesel involves some drawbacks, including its high production cost (70\% due to the starting vegetable oil) which represents the greatest restriction to be used as a sustainable energy source [1].

Biodiesel is obtained by the transesterification of triglycerides present in vegetable oils or animal fats [1]. This reaction is carried out in the presence of an alcohol and a catalyst. Four edible oils stand out in the production of biodiesel: rapeseed, sunflower, soy, and palm oil [2-6]. Biodiesel production can also be carried out using inedible oils as castor and Jatropha seeds [6-8]. In the European Union, approximately 13 percent of biodiesel is produced from sunflower oil. Nevertheless, in the USA, soybean oil makes up about 50 percent of biodiesel feedstock. Finally, there are other alternatives that can be used in the production of FAME that do not necessarily have to be vegetables. Within this group are animal fats among which stand out; beef tallow, lard, chicken's skin waste and fish oil [9-12]. It is also possible to obtain FAME from used cooking oils which makes it possible to revalue a residue [13,14]. Ethanol, propanol, butanol, and methanol are alcohols that can be used in the transesterification reaction, with the latter being the most used because it is the cheapest and most reactive. To select the type of alcohol it is important to know that the solubility of the oil increases with the length of the alcohol chain [1]. However, 
when the solubility increases, the ester content obtained in the reaction decreases. Therefore, conversions will be better using short-chain alcohols such as methanol. The transesterification reaction can be accelerated by acidic, basic, and enzymatic catalysis. Different experiments have been carried out with different catalysts in which the advantages and disadvantages of each are compared [1].

The basic catalysts are the most used in this type of reaction. With these catalysts, reaction times are considerably shorter than with acid catalysis. Its major drawback is that they can produce side reactions that give rise to free fatty acids that form soaps. In the case of basic homogeneous catalysis, $\mathrm{NaOH}$ and $\mathrm{KOH}$ are the most used. The optimum concentrations used are between $0.5-1 \%$ of the oil mass. However, high concentrations of alkali increase the solubility of methyl esters in the glycerol phase. On the other hand, low alkali concentrations decrease the conversion rate to FAME [1]. In this way, it is always necessary to carry out a preliminary study to optimise the catalyst concentration. The main disadvantages of acid catalysts are that they have very long reaction times in addition to causing unwanted by-products such as dialkyl ethers or glycerol ethers [1].

As for enzymatic catalysts, lipases are mainly used. They have certain advantages, such as the use of mild temperature, pressure, and $\mathrm{pH}$ conditions during the reaction process. It is not necessary to purify the ester or glycerin so that the washing process is avoided. In addition, transesterification of triglycerides and esterification of fatty acids occurs in a single step so that the starting materials can be used without pre-treatment. As for the disadvantages, it has long reaction times, poor efficiency, and high catalyst concentrations [1].

The production of biodiesel in situ is a new approach to obtain biodiesel directly from seeds. It was introduced by Harrington and Darcyevans $[15,16]$ and, in it, transesterification is carried out in a single step, thus reducing the number of operations and consequently the cost of production. The expensive costs used for oil extraction and its degumming in the production of biodiesel can be reduced since the refining of oilseeds is not necessary. In this method the alcohol has a double role: it extracts the oil and reacts with the triglycerides present in it. The efforts of current research in this field are aimed at reducing the solvent/oil molar ratio (6/1 in conventional transesterification and $>300 / 1$ in situ). A large amount of alcohol is necessary for the synthesis of biodiesel causing an increase in the cost of the process. We tried to find ways to reduce it. The possibility of using co-solvents that increase the solubility of the oil and, consequently, the reaction rate has been studied. The best results have been achieved with sunflower seeds and using diethoxymethane as co-solvent $\left(0.2 \mathrm{M} \mathrm{NaOH}\right.$, a solvent/oil molar ratio $101 / 1,20^{\circ} \mathrm{C}$ and 13 hours of reaction) obtaining a conversion rate to FAME of $98 \%$ [17].

Due to the immiscibility of alcohol with the oil at the beginning of the reaction, it is necessary to maintain intense and constant agitation to achieve a percentage of conversion to biodiesel greater than the $96.5 \%$ $(\mathrm{m} / \mathrm{m})$ required by European Standard EN14214. It is known that low-frequency ultrasound can be used to obtain emulsions of immiscible liquids. This is because the cavitation bubbles that are produced in the medium, due to the effect of ultrasound, form micro-jets that impact on the interface, causing currents that invade both liquids and accelerate the emulsion process [18]. These microjets can also disrupt cell 
walls, facilitating solvent to penetrate into the material and allowing the intracellular product release. Another mechanical effect caused by ultrasound may be increasing the contact surface area between the solvent and the material, permitting greater penetration of solvent into the sample. Knowing the importance of agitation for the transesterification reaction and knowing the effect that ultrasound produces in liquids, Stavarache et al. $[19,20]$ used this technique for the first time in the synthesis of biodiesel from vegetable oils. These authors found that ultrasound speeds up the reaction process, obtaining a $98 \%$ conversion yield to biodiesel in a few minutes, in addition to observing that the yield increased proportionally to the intensity of ultrasound. In recent years other works $[21,22]$ have demonstrated the efficient use of this technology in the production of biodiesel.

The objective of this study will be to apply ultrasonic technology in the process of transesterification in situ, using sunflower and soybean seeds. For this, parameters such as the methanol/oil ratio, reaction time, and catalyst concentration in the sono-transesterification process of these vegetable seeds will be optimised.

\section{Materials And Methods}

\subsection{Chemical reagents:}

Commercial sunflower seeds ( $22.8 \%$ protein, $49.6 \%$ fat, $8.2 \%$ carbohydrates, and $10.5 \%$ fiber), commercial yellow soybeans (33.7\% protein, $18.1 \%$ fat, $6.3 \%$ carbohydrates, and $21.9 \%$ fiber), hydrochloric acid (Scharlau, 37\%), methanol (Panreac, 99.8\%, maximum water content 0.005\%), n-Hexane (Scharlau, 96\%), sodium hydroxide (Panreac, > 97.5\%) and phosphomolibic acid (Merck), methyl acetate (Scharlau), isooctane (Scharlau), methyl tert-butyl ether (Scharlau), and 2-propanol (Scharlau).

\subsection{Experimental devices:}

Ultrasonic generator $20 \mathrm{kHz}$ frequency (Hielscher, 250W, Sonotrode diameter: $12 \mathrm{~mm}$ ); in all experiences, a calorimetric power of 106 W was used. HPLC (High-Performance Liquid Chromatography) Agilent 1260 Infinity equipped with an Evaporative Light Scattering Detector (ELSD) 385 with a normal phase silica column. Gas-mass chromatograph Agilent equipped with mass detector (GC-MS), automatic injector, and capillary column.

\subsection{Biodiesel production from sunflower and soybean seeds:}

\section{Seed Drying Process}

The seeds were ground in a conventional grinder and were subjected to a drying process. For this, it was kept in an oven at a temperature of $40^{\circ} \mathrm{C}$ and was weighed regularly until a constant weight was observed. The seeds were stored in an oven at $40^{\circ} \mathrm{C}$.

\section{Oil extraction}


Tests were carried out to determine the ideal solvent as well as the optimum seed/solvent ratio for oil extraction. For these tests, a certain amount of seeds were added to the reactor, the solvent was subsequently added in the chosen proportion, and the mixture was sonicated for different time lengths. Once this operation was done, the seeds were separated by centrifugation. Then, to remove the solvent from the liquid sample, it was introduced into a concentrator at $40^{\circ} \mathrm{C}$ with a stream of $\mathrm{N}_{2}$.

\section{Transesterification reaction}

The reaction was carried out in two steps for sunflower seeds or, in only one, for soybean seeds. In the production of biodiesel from sunflower seeds, the first step was an extraction of the oil with hexane and subsequent filtration of the seeds. In the second step, $\mathrm{NaOH}$ and $\mathrm{MeOH}$ were added to the liquid mixture (oil+hexane) to produce the sono-transesterification reaction. The production of biodiesel from soybeans was done in a single step by mixing the seeds, hexane, methanol, and $\mathrm{NaOH}$ in the reactor and subsequent sonication at different times.

\subsection{Biodiesel characterisation:}

Biodiesel analysis has been achieved through different techniques: Thin Layer Chromatography (TLC), HPLC-ELSD, and GC-MS

\section{$\underline{\text { TLC analysis }}$}

Triolein and methyl oleate patterns were used to represent to triglycerides and methyl esters, respectively. As a stationary phase, silica with an aluminum support was used and as a mobile phase, hexane and methyl acetate in a 9/1 ratio

The plates were revealed with phosphomolibic acid, which when in contact with sunlight, produces dark spots. The phosphomolibic acid was prepared by weighing $5 \mathrm{~g}$ of phosphomolibic acid and dissolving it in $100 \mathrm{~mL}$ of ethanol (96\%).

\section{$\underline{\text { HPLC-ELSD analysis }}$}

The chromatographic separation of the different species of lipids was carried out with a silica normalphase ACE $(250 \mathrm{~mm} \times 4.6 \mathrm{~mm}$ i.d., $5 \mu \mathrm{m})$ column maintained at $30^{\circ} \mathrm{C}$ using a ternary gradient: $0-3 \mathrm{~min}$, 95.5\% A and 0.5\% B; 5 min, 70\% A and 30\% B; 9 min, 70\% A and 30\% B; 10 min, 56\% A, 24\% B and 20\%C; $16 \mathrm{~min}, 56 \% \mathrm{~A}, 24 \% \mathrm{~B}$ and $20 \% \mathrm{C} ; 17 \mathrm{~min}, 95.5 \% \mathrm{~A}$ and $0.5 \% \mathrm{~B} ; 19 \mathrm{~min}, 95.5 \% \mathrm{~A}$ and $0.5 \%$ B. Eluent $\mathrm{A}$ : isooctane, Eluent B: methyl tert-butyl ether, and Eluent C: 2-propanol. The flow rate was $2.0 \mathrm{~mL} / \mathrm{min}$. Lipid species were identified using commercial standards like triacylglycerols, diacylglycerols, monoacylglycerols, and free fatty acids.

\section{GC-MS analysis}


Previous to analysis on an Agilent GC-MS, FAMEs were freshly prepared by base-catalysed methanolysis of the glycerides (KOH in methanol). FAMEs were separated using an HP 88 capillary column $(100 \mathrm{~m} \times 0.25 \mathrm{~mm}$, i.d. $0.2 \mu \mathrm{m})$. A $1 \mu \mathrm{L}$ sample was injected using a split ratio of 1:100. The column was held at $175^{\circ} \mathrm{C}$ for $10 \mathrm{~min}$ after injection, the temperature increase was programmed at $3^{\circ} \mathrm{C} / \mathrm{min}$ to $220^{\circ} \mathrm{C}$ and maintained for 20 more minutes. Helium was used as the carrier gas at a constant column flow rate of $1.5 \mathrm{~mL} / \mathrm{min}$. Fatty acids were identified by comparing their retention times and mass spectra (NIST MassSpectral Library Version 2.0) with those obtained from the standards.

\section{Results And Discussion}

\subsection{Synthesis of biodiesel from sunflower seeds}

Oil Extraction: Initial experiments were performed using as the solvent: hexane, methanol, or a 50:50 mixture of methanol:hexane. In the last two cases, after sonicating and centrifuging the samples, a whitish layer deposited between the phases of the sample. Sunflower seeds contain mucilage which is a protective layer that some seeds have, and it is extracted along with the oil when extraction is done with polar solvents. Similar behaviour was observed by Baümler et al. [23,24]. They studied and compared the ethanolic extraction of oil from sunflower collets with the extraction with hexane, and they proved that ethanol has a higher extraction power than hexane. Ethanol showed great ability to extract sugar, phospholipids and tocopherols, extracting over $75 \%$ of the initial sugar content. The mucilage that we extracted with methanol can be related to these types of compounds. This fact forced us to carry out the extraction only using hexane as a solvent.

Before addressing the synthesis of biodiesel, several experiments were performed with the aim of finding the optimal conditions to extract all the oil content present in sunflower seeds. Table 1 shows the main experiments performed for this extraction, varying the seed/hexane ratio $(\mathrm{g} / \mathrm{mL})$ as well as the sonication time. This table also includes the yield of extracted oil and compares it with what was expected for a fat content of the seed of $49.6 \%$.

Table1. Sonochemical extraction of oil from sunflower seeds and hexane as solvent 


\begin{tabular}{|c|c|c|c|c|c|}
\hline Sample & $\begin{array}{l}\text { Sunflower seed/hexane ratio } \\
(\mathrm{g} / \mathrm{mL})\end{array}$ & $\begin{array}{l}\text { Sonication time } \\
(\min )\end{array}$ & $\begin{array}{l}\text { Content } \\
\text { oil* } \\
\text { (g) }\end{array}$ & $\begin{array}{l}\text { Extracted } \\
\text { oil } \\
\text { (g) }\end{array}$ & $\begin{array}{l}\text { Oil } \\
\text { yield } \\
\text { (\%) }\end{array}$ \\
\hline 1 & $6 / 30$ & 1 & 2.98 & 2.81 & 94.3 \\
\hline 2 & $6 / 30$ & 3 & 2.98 & 2.65 & 88.9 \\
\hline 3 & $6 / 30$ & 6 & 2.98 & 2.71 & 90.9 \\
\hline 4 & $9 / 30$ & 1 & 4.46 & 3.50 & 78.5 \\
\hline 5 & $9 / 30$ & 3 & 4.46 & 3.30 & 74.0 \\
\hline 6 & $12 / 30$ & 1 & 5.88 & 4.18 & 71.1 \\
\hline 7 & $12 / 30$ & 3 & 5.88 & 3.40 & 57.8 \\
\hline
\end{tabular}

\section{*Amount calculated for an oil content of $49.6 \%$}

The results showed a higher yield (94\%) when adding $6 \mathrm{~g}$ of seeds and $30 \mathrm{~mL}$ of solvent with 1 minute of sonication. The optimal ratio for oil extraction in sunflower seeds is $1 / 5$. The table also shows the yields with different sonication times. Similar yields at 1, 3 or 6 minutes of sonication were observed. Therefore, with these reaction conditions, with only one minute of sonication, it is possible to extract more than $90 \%$ of the oil contained in the sunflower seed.

So far, there are few published works on ultrasonic-assisted extraction of sunflower seed oil. Studies on this raw material have mainly been directed to the extraction of other types of compounds, such as phenolics [25]. Milenković et al. [26] applied two ultrasonic-assisted oil extraction techniques to sunflower seeds. A modified Soxhlet apparatus with a ultrasonic generator and a classical batch reactor with ultrasonic generator were used in this research. With the first device, a positive contribution of $1-1.5 \%$ was observed in the extraction with the use of ultrasound. However, the extraction times are 6 hours for a seed/solvent ratio of $1 / 10$. Using the second device, most of the oil was extracted in 20 minutes of exposure to ultrasound $(>95 \%$ ) with the same ratio of $1 / 10$ seed/solvent. Similar results were obtained by Moradi et al. working also with this type of seeds [27]. Using n-hexane as extracting solvent and a seed/solvent ratio $1 / 12$, ultrasound frequency $24 \mathrm{kHz}$ and a time of 2 hours for a complete extraction. In our case we have used a seed/solvent ratio of $1 / 5$ and only 1 minute of sonication and the extraction achieved $94.3 \%$ of the oil contained in the sunflower seed. The secret is to increase the applied ultrasonic power. Shalmashl [28], using tea seeds, showed that the oil extraction yield of tea increased when increasing the ultrasonic power. When the power was increased from 10 to $50 \mathrm{~W}$, the yield of tea seed oil was increased from $46.23 \%$ to $85.21 \%$. However, a further increase in the power showed only a moderate rise in yield. Our experience tells us that the exposure time to ultrasound should be controlled and only an appropriate time applied, since longer exposure times can degrade the extracted oil (see Table 1). Most of the works found in the literature use hours to sono-extract the oil from the seeds. However, it is very 
important to control sonication time when using high power ultrasound. Senrayan et al. [29], using Carica papaya seeds, obtained a maximum oil recovery when ultrasound-assisted extraction was carried out at a $1 / 13(\mathrm{~g} / \mathrm{mL})$ seed/solvent ratio, $80 \%$ amplitude of ultrasonic power and an extraction time of 7 minutes.

Taking these results into account, the production of biodiesel from sunflower seeds must be carried out in two steps: in the first one, hexane extraction is carried out with the subsequent filtration of the seeds, and in the second, after addition of $\mathrm{NaOH}$ and $\mathrm{MeOH}$, the sono-transesterification reaction is carried out.

Transesterification reaction. In the transesterification stage, biodiesel synthesis experiments have been carried out at different concentrations of methoxide $(0.83,0.50,0.25$, and $0.00 \mathrm{M})$ and with different volumes of this $(7.50,5.00$, and $2.50 \mathrm{~mL})$ added to the oil mixture dissolved in hexane. In all experiments, the seed/hexane ratio starting amounts were kept constant: $6 / 30(\mathrm{~g} / \mathrm{mL})$ and analysed qualitatively by TLC and quantitatively by HPLC. With this last method, the percentage of the ester with respect to the triglycerides present in the final mixture was obtained. Table 2 shows this conversion analysed by HPLC for a sonication time of 1 minute. The results show very high conversions in all cases, obtaining, in almost all experiments, percentages greater than $99 \%$. Note that in the absence of a catalyst (sample 10), no conversion to FAME was observed. On the other hand, it should be remembered that when biodiesel is produced, it is very important to achieve a high conversion efficiency to FAME with the minimum amount of catalyst, both to avoid the formation of soaps and to simplify the washing process. Therefore, in view of the results, the conditions of sample 9 can be selected as the most suitable to obtain a high conversion rate to FAME in a sonoreaction time of only one minute.

Few are the published works on the production of biodiesel in situ from sunflower seeds. Siler-Marinkovic and Tomasevic [30] used sunflower seeds with an oil content of $55.6 \%$ to produce biodiesel in situ by acid catalysis, using methanol as a solvent and without applying ultrasound. In all their research they reached a biodiesel yield $>90 \%$, although the reaction times were never less than 60 minutes. Siatis et al. [31] shortened conversion times to FAME to 30 minutes, using an ultrasonic bath and a mixture of hexane methanol $(50 \mathrm{~mL} / 3 \mathrm{~mL})$ and $10 \mathrm{~g}$ of seeds. The conversion yield was $93 \%$. Georgogianni et al. [32], using low frequency ultrasonication $(24 \mathrm{kHz})$, alkaline transesterification of sunflower seed oil with a molar ratio of methanol to oil of $7 / 1$, obtained high yields of methyl esters (95\%) after a short reaction time (20 minutes). Gama et al. [33] also used in situ transesterification of sunflower seed oil with methanol on $\mathrm{KOH}$ as basic catalyst for the production of biodiesel. The activity of $\mathrm{KOH}$ was evaluated using an oil to methanol ratio of $1 / 90$ without ultrasound. $\mathrm{KOH}$ was shown to be an active catalyst, leading to total conversion in biodiesel after 1 hour reaction time. The shortest reaction times were obtained by Zhen et al. [17] using methanol assisted by diethoxymethane (DEM) as a cosolvent without applying ultrasound in the process. When the in situ transesterification was carried out with a molar ratio of methanol to oil of $101.39 / 1$ and a molar ratio of DEM/oil of 57.85/1; a product containing $97.7 \%$ FAME was obtained in a reaction time of 13 minutes. We have managed to shorten the reaction time to just 1 minute.

Table 2: Sono-transesterification, in two steps (1 $\mathrm{min}$ for extration and $1 \mathrm{~min}$ for transesterification), of sunflower for the production of biodiesel. 


\begin{tabular}{|lllcl|}
\hline Sample & $\begin{array}{l}\text { Sunflower } \\
\text { seed/hexane ratio } \\
(\mathrm{g} / \mathrm{mL})\end{array}$ & $\begin{array}{l}\text { Methoxide concentration } \\
(\mathrm{M})\end{array}$ & $\begin{array}{c}\text { Methoxide } \\
\text { Volume } \\
(\mathrm{mL})\end{array}$ & $\begin{array}{l}\text { Biodiesel } \\
\text { yield }\end{array}$ \\
\hline 1 & $6 / 30$ & 0.83 & 7.5 & - \\
\hline 2 & $6 / 30$ & 0.83 & 5.0 & 99.7 \\
\hline 3 & $6 / 30$ & 0.83 & 2.5 & 99.8 \\
\hline 4 & $6 / 30$ & 0.50 & 7.5 & 94.2 \\
\hline 5 & $6 / 30$ & 0.50 & 5.0 & 98.8 \\
\hline 6 & $6 / 30$ & 0.50 & 2.5 & 99.7 \\
\hline 7 & $6 / 30$ & 0.25 & 7.5 & 99.6 \\
\hline 8 & $6 / 30$ & 0.25 & 5.0 & 99.5 \\
\hline 9 & $6 / 30$ & 0.25 & 2.5 & 99.3 \\
\hline 10 & $6 / 30$ & 0.00 & 7.5 & 0.00 \\
\hline
\end{tabular}

\subsection{Synthesis of biodiesel from soybeans}

Oil Extraction: For the extraction of the oil contained in soybean seeds, hexane and methanol were also used as solvents, as well as a 50:50 mixture of these. In this case, the presence of mucilage was also observed, although in smaller quantities than in sunflower seeds. No amount of mucilage was observed when hexane was used as the solvent in the oil extraction process. Thus, although it was observed that the extraction process had a higher yield in the presence of methanol, it was decided to use only hexane as the solvent. Table 3 shows the main experiments performed for this extraction, varying the seed/hexane ratio $(\mathrm{g} / \mathrm{mL})$ as well as the sonication time. This table also includes the yield of extracted oil and compares it with that expected for a fat content of the seed of $18.1 \%$.

Table 3. Sonochemical extraction of oil from soybean seeds and n-hexane as solvent 


\begin{tabular}{|llllll|}
\hline Sample & $\begin{array}{l}\text { Soybean seed/hexane ratio } \\
(\mathrm{g} / \mathrm{mL})\end{array}$ & $\begin{array}{l}\text { Sonication } \\
\text { time } \\
(\mathrm{min})\end{array}$ & $\begin{array}{l}\text { Theoretical oil* } \\
(\mathrm{g})\end{array}$ & $\begin{array}{l}\text { Extracted oil } \\
(\mathrm{g})\end{array}$ & $\begin{array}{c}\text { Oil } \\
\text { Yield } \\
(\%)\end{array}$ \\
\hline 1 & $3 / 30$ & 1 & 0.54 & 0.32 & 59.3 \\
\hline 2 & $6 / 30$ & 1 & 1.09 & 0.46 & 42.2 \\
\hline 3 & $9 / 30$ & 1 & 1.63 & 0.68 & 41.7 \\
\hline 5 & $12 / 30$ & 1 & 2.17 & 0.92 & 42.4 \\
\hline 5 & $12 / 30$ & 3 & 2.17 & 0.83 & 38.2 \\
\hline
\end{tabular}

\section{*Amount calculated for an oil content of $18.1 \%$}

The yields shown in Table 3 are, in all cases, lower than those obtained in sunflower seeds. A limiting effect of the solvent (comparing experiments 2-4) was also observed since, although the amount of oil increases with the grams of seeds added, the yield remains constant. Comparing experiments four and five of this table, it is observed that increasing the exposure time to ultrasound does not improve the oil extraction yield. Probably the longest exposure time to ultrasound degrades the oil already extracted. The results also reveal that the proportions with which higher yields are achieved are 3:30 with one minute of sonication.

There are also few published works on the application of ultrasound for the extraction of oil contained in soybeans. Li et al. [34,35] applied $20 \mathrm{kHz}$ high-intensity ultrasound during extraction of oil from two varieties of soybeans. The highest yield result of $12.21 \mathrm{~g}$ from $100 \mathrm{~g}$ soybeans $(19.2 \%$ oil content in soybean seeds) was obtained using $150 \mathrm{~mL}$ of a $3: 2$ hexane to isopropanol mixture under $47.6 \mathrm{~W} / \mathrm{cm}^{2}$ and 3 hours of sonication. In our case, we chose to perform the extraction only in hexane as we already showed in the case of sunflower oil extraction: alcohols favour the extraction of phospholipids, pigments and sugars that could become part of the biodiesel by contaminating it. Kanitkar et al. [36] demonstrated that shorter extraction times are necessary when microwave radiation is used. They exposed a mixture solvent to a feedstock ratio of $3 / 1$ to microwave radiation at different temperatures. The results showed that the oil yield changed with temperature and achieved a maximum value in a relatively short time (order of minutes). Maximum oil yields of $17.3 \%$ and $120^{\circ} \mathrm{C}$ were achieved by microwave extraction. In our case, with only 1 minute, we have achieved a yield of $59.3 \%$ (see Table 3 ).

Transesterification reaction: After oil extraction, tests were carried out to obtain biodiesel by transesterification in situ in a single step. Since the presence of methanol is necessary for the synthesis of biodiesel and this solvent favours the extraction of mucilage, several experiments were carried out with different amounts of methanol (always less than $20 \%$ of the total volume). In all these tests, no traces of this substance were observed, so it was decided to continue with the synthesis in a single step. Several experiments were conducted in which the amounts of seed/hexane $(2.5 \mathrm{~g} / 25 \mathrm{~mL})$ and $1 \mathrm{~min}$ of sonication 
time remained constant. Two concentrations of starting methoxide ( 0.12 and $1 \mathrm{M})$ were used, and different volumes of both methoxide and methanol were added. Table 4 shows the amounts added in each experiment and the results obtained by TLC.

Table 4: Sono-transesterification in one step of soybean for the production of biodiesel. A same starting soybean/n-hexane ratio $(2.5 \mathrm{~g} / 25 \mathrm{~mL})$ was used in all samples. $1 \mathrm{~min}$ of sonication time.

\begin{tabular}{|llllll|}
\hline Sample & $\begin{array}{l}\text { Methoxide } \\
\text { volume } \\
(\mathrm{mL})\end{array}$ & $\begin{array}{l}\text { Methoxide } \\
\text { concentration }(\mathrm{M})\end{array}$ & $\begin{array}{l}\mathrm{MeOH} \\
\text { Volume } \\
(\mathrm{mL})\end{array}$ & $\begin{array}{l}\text { MeOH total } \\
\text { volumen } \\
(\mathrm{mL})\end{array}$ & $\begin{array}{l}\text { Ester } \\
\text { presence in } \\
\text { TLC }\end{array}$ \\
\hline 1 & 0.50 & 0.12 & 0.00 & 0.50 & No \\
\hline 2 & 0.83 & 0.12 & 0.00 & 0.80 & No \\
\hline 3 & 5.00 & 0.12 & 0.00 & 5.00 & Yes* \\
\hline 4 & 0.50 & 0.12 & 4.50 & 5.00 & No \\
\hline 5 & 5.00 & 1.00 & 0.00 & 5.00 & Yes \\
\hline 7 & 2.50 & 1.00 & 2.50 & 5.00 & Yes \\
\hline 8 & 1.25 & 1.00 & 3.75 & 5.00 & Yes* \\
\hline 9 & 1.25 & 1.00 & 1.25 & 2.50 & Yes $^{*}$ \\
\hline 10 & 1.50 & 1.00 & 0.62 & 1.25 & Yes $^{*}$ \\
\hline
\end{tabular}

* The formation of the ester was observed in TLC, although there are also unreacted triglycerides.

In view of the results shown in this table, only two experiments with higher $\mathrm{NaOH}$ content showed a significant amount of ester and lack of oil signal by TLC. Sample 5 (was chosen because it has a lower $\mathrm{NaOH}$ content than sample 6) was repeated three times and analysed by HPLC. In all cases, the amount of ester versus triglyceride in the biodiesel formed was greater than $99 \%$.

The work of Kddiran et al. [37] was one of the first published on alcoholysis in situ of soybean seeds in different alcohols. These authors found that maceration before in situ alcoholysis caused an appreciable increase in the amount of the oil. With maceration, approximately $40 \%$ of the soybean oil was transferred to the methanol phase, and the methyl ester content of this oil reached $55 \%$ for 3 hours reaction time and ultrasonic absence. In a more recent work, Haas and Scott [38,39], using dry flakes of soybean, achieved an optimal transesterification in reactions containing $5 \mathrm{~g}$ of flakes and $12 \mathrm{~mL}$ of $0.10 \mathrm{~N} \mathrm{NaOH}$ in methanol, 10 hours of reaction time and the absence of ultrasound. More recently, Tuntiwiwattanapun et al. [40] showed that Isopropanol is an effective solvent for use in soybean oil extraction. This solvent was used in the in situ transesterification process, with up to $85 \%$ of the biodiesel yield and a reaction time of 90 
minutes. In none of the above works has ultrasound been applied in the transesterification process. If we compare these results with those shown by us, clearly ultrasound-assisted reduces the time of biodiesel production from hours to 1 minute.

\subsection{Analysis of fatty acids in oil and biodiesel}

The oils extracted and biodiesel produced from the soybean and sunflower seeds were analysed by gas chromatography to check if the extraction and transesterification process using ultrasound altered their composition.

Figure 1 and Table 5 shows the oil and biodiesel chromatograms obtained from sunflower seeds.

Table 5: Fatty acid composition of oil and biodiesel obtained from sunflower seeds. $t_{R}$ is the retention time in minutes

\begin{tabular}{|llll|}
\hline Peak & $t_{R}(\min )$ & $\begin{array}{l}\text { Sunflower } \\
\text { oil (\%) }\end{array}$ & Sunflower biodiesel (\%) \\
\hline A & 12.963 & 6.115 & 5.360 \\
\hline B & 16.477 & 3.039 & 5.399 \\
\hline C & 17.624 & 31.167 & 21.809 \\
\hline D & 19.364 & 59.430 & 67.068 \\
E & 24.497 & 0.248 & 0.364 \\
\hline
\end{tabular}

The results of Table 5 show quite a significant difference between the majority peaks $C$ and $D$. The conversion of oleic acid to linoleic acid probably occurs sonochemically. This conversion could be explained by the presence of $\mathrm{OH}$ radicals produced by an intense field of ultrasound [18]. On the other hand, the hydrogen abstraction reaction produced by these radicals in the presence of hydrocarbons is well known. This abstraction generates alkyl radicals that could explain the conversion of oleic acid into linoleic acid observed in sunflower samples.

As can be observed in Figure 2 and Table 6, in the case of soybeans, the fatty acid composition of the extracted oil and biodiesel are very similar and, therefore, ultrasound does not alter its composition.

Table 6: Fatty acid composition of oil and biodiesel obtained from soybean seeds. $t_{R}$ is the retention time in minutes. 


\begin{tabular}{|llll|}
\hline Peak & $t_{R}(\min )$ & $\begin{array}{l}\text { Soybean } \\
\text { oil }\end{array}$ & $\begin{array}{l}\text { Soybean biodiesel } \\
\%\end{array}$ \\
& & $(\%)$ & \\
\hline A & 12.962 & 12.387 & 13.248 \\
\hline B & 16.476 & 3.990 & 3.701 \\
\hline C & 17.617 & 22.637 & 21.688 \\
\hline D & 19.355 & 52.569 & 52.957 \\
\hline E & 21.380 & 8.282 & 8.285 \\
\hline F & 24.492 & 0.134 & 0.120 \\
\hline
\end{tabular}

From the results obtained in this work, the in situ sono-transesterification is a promising approach to synthesis biodiesel from seeds directly. Few studies on this subject are found in the bibliography. The majority have utilised liquid oil directly instead of solid oilseeds. Within the latter, still fewer were performed on transesterification in situ from edible oil seeds. The results published so far using an in situ transesterification with soybeans and basic catalysis required several hours to complete the transesterification reaction [37-40]. In our case, using a concentration of $0.5 \mathrm{M} \mathrm{NaOH}$, a solvent/seed molar ratio of 638/1, a one-minute reaction time in the presence of an ultrasonic field of $20 \mathrm{kHz}$ frequency, and a calorimetric power of $106 \mathrm{~W}$, we have achieved a conversion rate greater than $99 \%$.

The results with sunflower seeds were also good, although with the inconvenience of having to produce biodiesel through two steps. The best results found in the literature using in situ transesterification in the presence of an ultrasonic field with this type of seeds showed a conversion rate of $95 \%$ of methyl esters after approximately 20 min of reaction time [32]. In our case, a percentage higher than $99 \%$ has been achieved using room temperature and one minute of sonication.

The most significant of our results is having achieved such high biodiesel yields with just one minute of reaction simply by replacing pure methanol with a hexane/methanol mixture. These results offer us the possibility of designing flow reactors that, with very little residence time within an ultrasonic field, achieve very high biodiesel yields.

In terms of energy consumption, mechanical stirring usually requires higher energy consumption than ultrasonication. It was reported that ultrasonication only required one-third to half of the energy that was consumed by mechanical agitation $[21,22]$. Therefore, we think that the presence of an ultrasonic field in the process of biodiesel production from seeds has enormous potential when it comes to reducing production costs. 


\section{Conclusions}

Production of biodiesel from sunflower and soybean seeds is feasible by in situ processes. The conversions obtained by this method are considerably higher than by other conventional processes. The use of hexane as a co-solvent reduced the alcohol requirement for high-efficiency biodiesel conversion. Starting from $6 \mathrm{~g}$ of ground sunflower seeds, $30 \mathrm{~mL}$ of hexane, applying 1 minute of sonication $(20 \mathrm{kHz}$, $106 \mathrm{~W}$ ), separating the seeds by centrifugation, and subsequent addition of $2.5 \mathrm{~mL}$ of $0.25 \mathrm{M}$ sodium methoxide plus another minute of sonication, it is possible to obtain a biodiesel with a percentage in FAME greater than $99 \%$. In the case of soybeans, the process can occur in a single step with subsequent centrifugation of the seeds. Thus, with the following conditions: $2.5 \mathrm{~g}$ of soybean seeds, $25 \mathrm{~mL}$ of hexane, $2.5 \mathrm{~mL}$ of $\mathrm{MeOH}$, and $2.5 \mathrm{~mL}$ of $1 \mathrm{M}$ methoxide with one minute of sonication $(20 \mathrm{kHz}, 106 \mathrm{~W})$, it is possible to obtain a conversion rate to biodiesel greater than $99 \%$.

\section{Abbreviations}

FAME: Fatty Acid Methyl Esters

TLC: Thin Layer Chromatography

ELSD: Evaporative Light Scattering Detector

GC-MS: Gas Chromatography with mass detector

HPLC: High-Performance Liquid Chromatography

DEM: Diethoxymethane

$t_{R}$ : retention time

\section{Declarations}

\section{Ethics approval and consent to participate}

Not applicable.

\section{Consent for publication}

The authors agree to publish this work in Bioresources and Bioprocessing

\section{Availability of data and materials}

Not applicable.

\section{Competing interests}


The authors declare no competing financial and non-financial interests

\section{Funding}

Funding was provided by The Universidad Autónoma de Madrid

\section{Authors' contributions}

DRD conceived the project. AQG was responsible for all experiments. DRD oversaw the project. DRD and AQG wrote the manuscript and prepared all figures. All authors read and approved the final manuscript.

\section{Acknowledgements}

We appreciate the help provided by the Healthy Lipids Research Group at Universidad Autónoma Madrid, especially Dr Pilar Luna.

\section{Authors' information (optional)}

Not applicable

\section{References}

1. Mittelbach M, Remschmidt C. Biodiesel/ the comprehensive handbook. Publisher: Martin Mittelbach, 2004, ISBN 3-200-00249-2

2. Georgogianni KG, Katsoulidis AK, Pomonis PJ, Manos G, Kontominas MG (2009) Transesterification of rapeseed oil for the production of biodiesel using homogeneous and heterogeneous catalysis. Fuel Process Technol 90(7-8):1016-1022

3. Vujicic DJ, Comic D, Zarubica A, Micic R, Boskovic G (2010) Kinetics of biodiesel synthesis from sunflower oil over CaO heterogeneous catalyst. Fuel 89(8):2054-2061

4. Mekhilef S, Siga S, Saidur R (2011) A review on palm oil biodiesel as a source of renewable fuel. Renewable Sustainable Energy Reviews 15(4):1937-1949

5. Hoekman K, Broch A, Robbins C, Ceniceros E, Natarajan M (2012) Review of biodiesel composition, properties, and specifications. Renew Sustain Energy Rev 16(1):143-169

6. Singh D, Sharma D, Soni SL, Sharma S, Kumar Sharma P, Jhalani A, A review on feedstocks, production processes, and yield for different generations of biodiesel. FUEL, Vol 262, UNSP 116553, 2020

7. Kumar D, Kumar G, Poonam, Singh CP (2010) Ultrasonic-assisted transesterification of Jatropha curcus oil using solid catalyst. Na/SiO2 Ultrasonics Sonochemistry 17(5):839-844

8. Moradi G, Ghanadi T. An experimental investigation of direct biodiesel production from castor seed using waste resource as economical catalyst. Environmental Progress $\delta$ Sustainable Energy, Vol 38 (5), 2019, №13180 
9. Okwundu OS, El-Shazly AH, Elkady M. Comparative effect of reaction time on biodiesel production from low free fatty acid beef tallow: a definition of product yield. SN Applied Sciences, Vol 1 (2), 2019, Nº140

10. Casiello M, Catucci L, Fracassi F, Fusco C, Laurenza AG, di Bitonto L, Pastore C, D'Accolti L and Nacci A. ZnO/Ionic Liquid Catalyzed Biodiesel Production from Renewable and Waste Lipids as Feedstocks. Catalysts, Vol 9 (1), 2019, N071

11. Catarino M, Soares Dias AP, Ramos M. Double benefit biodiesel produced from waste frying oils and animal fats. Wastes - solutions, Treatments Opportunities II, 2018, 153-159, DOI:10.1201/9781315206172-25

12. Mounir A, Touzani A, Benhima R (2019) Synthesis of biodiesel from chicken's skin waste by homogeneous transesterification. Int J Sustain Eng 12(4):272-280

13. Dimian AC, Kiss AA. Eco-efficient processes for biodiesel production from waste lipids. Journal of Cleaner Production, Vol 239, 2019, № UNSP 118073

14. di Bitonto L, Pastore $C$ (2019) Metal hydrated-salts as efficient and reusable catalysts for pre-treating waste cooking oils and animal fats for an effective production of biodiesel. Renewable Energy 143:1193-1200

15. Harrington KJ, Darcyevans C (1985) A comparison of conventional and insitu methods of transesterification of seed oil from a series of sunflower cultivars. J Am Oil Chem Soc 62(6):1009-1013

16. Harrington KJ, Darcyevans C (1985) Trans-esterification insitu of sunflower seed oil. Industrial Engineering Chemistry Product Research Development 24(2):314-318

17. Zeng J, Xiaodong W, Bing Z et ál.. Rapid In Situ Transesterification of Sunflower Oil. Industrial \& Engineering Chemistry Research, Vol 48 (2), 2009, 850-856

18. Mason TJ (1999) Sonochemistry: current uses and future prospects in the chemical and processing industries. Philosophical Transactions of the Royal Society A-Mathematical Physical Engineering Sciences 357(1751):355-369

19. Stavarache C, Vinatoru M, Nishimura R (2003) et ál. Conversion of vegetable oil to biodiesel using ultrasonic irradiation. Chem Lett 32(8):716-717

20. Stavarache C, Vinatoru M, Maeda Y (2006) Ultrasonic versus silent methylation of vegetable oils. Ultrason Sonochem 13(5):401-407

21. Veljkovi VB, Avramovi JM, Stamenkovi OS (2012) Biodiesel production by ultrasound-assisted transesterification: State of the art and the perspectives. Renew Sustain Energy Rev 16:1193-1209

22. Tan SX, Lim S, Ong HC, Pang YL (2019) State of the art review on development of ultrasoundassisted catalytic transesterification process for biodiesel production. Fuel 235:886-907

23. Baumler ER, Carrin ME, Carelli AA (2017) Diffusion of tocopherols, phospholipids and sugars during oil extraction from sunflower collets using ethanol as solvent. JOURNAL OF FOOD ENGINEERING 194:1-8 
24. Baumler ER, Carrin ME, Carelli AA (2016) Extraction of sunflower oil using ethanol as solvent. JOURNAL OF FOOD ENGINEERING 178:190-197

25. Zardo I, Andressa de Espindola S, Ferreira Marczak LD et ál..Optimization of Ultrasound Assisted Extraction of Phenolic Compounds from Sunflower Seed Cake Using Response Surface Methodology. WASTE AND BIOMASS VALORIZATION, Vol 10, № 1, 2019, 33-44

26. Milenković1 DD, Milosavljević MM (2018) Bojić ALj. Ultrasound-assisted extraction of sunflower oil from the cake after sunflower seed pressing. Journal of Agricultural Sciences Vol 63(2):195-204

27. Moradi N, Rahimi M, Moeini A, Parsamoghadam MA (2018) Impact of ultrasound on oil yield and content of functional food ingredients at the oil extraction from sunflower. SEPARATION SCIENCE AND TECHNOLOGY 53(No2):261-276

28. SHALMASHI A. ULTRASOUND-ASSISTED EXTRACTION OF OIL, FROM TEA SEEDS. J Food Lipids 16 (2009) 465-474.)

29. Senrayan J, Venkatachalam S (2019) A short extraction time of vegetable oil from Carica papaya L. seeds using continuous ultrasound acoustic cavitation: Analysis of fatty acid profile and thermal behavior. JOURNAL OF FOOD PROCESS ENGINEERING 42(1):e12950

30. Siler-Marinkovic S, Tomasevic A (1998) Transesterification of sunflower oil in situ. FUEL Vol 77(12):1389-1391

31. Siatis NG, Kimbaris AC, Pappas CS, Tarantilis PA, Polissiou MG. Improvement of Biodiesel Production Based on the Application of Ultrasound: Monitoring of the Procedure by FTIR Spectroscopy. JAOCS, Vol. 83, no. 1, 2006, 53-56

32. Georgogianni KG, Kontominas MG, Pomonis PJ et ál.. Conventional and in situ transesterification of sunflower seed oil for the production of biodiesel. Fuel Processing Technology, Vol 89 (5), 2008, 503-509

33. Gama PE, Gil RADS, Lachter ER (2010) Biodiesel production by in situ transesterification of sunflower seeds by homogeneous and heterogeneous catalysis. QUIMICA NOVA 33(9):1859-1862

34. Li H, Pordesimo LO, Weiss J, Wilhelm LR (2004) Microwave and ultrasound assisted extraction of soybean oil. American Society of Agricultural Biological Engineers 47(No:4):1187-1194

35. Li HZ, Pordesimo L, Weiss J (2004) High intensity ultrasound-assisted extraction of oil from soybeans. J FOOD RESEARCH INTERNATIONAL 37 No(7):731-738

36. Kanitkar A, Sabliov CM, Balasubramanian S, Lima M, Bolder D (2011) Microwave assisted extraction of soybean and rice bran oil: yield and extraction kinetics. AmericanSociety of Agricultural Biological Engineers; 54(4):1387-1394

37. Kildiran G, Yucel SO, Turkay S. In-situ alcoholysis of soybean oil JOURNAL OF THE AMERICAN OIL CHEMISTS SOCIETY Vol 73 No 2, 1996, 225-228

38. Haas MJ, Scott KM (2007) Moisture removal substantially improves the efficiency of in Situ biodiesel production from soybeans. Journal of the American Oil Chemists' Society 84:197-204.

doi:10.1017/S11746-006-1024-2

Page 17/19 
39. Makareviciene V, Sendzikiene E, Gumbyte M. Application of Simultaneous Oil Extraction and Transesterification in Biodiesel Fuel Synthesis: A Review ENERGIES Vol 13, No, 2020, 2204

40. Tuntiwiwattanapun N, Tongcumpou Ch, Wiesenborn D (2016) Optimization of alcoholic soybean oil extraction as a step towards developing in-situ transesterification for fatty acid isopropyl esters. INDUSTRIAL CROPS AND PRODUCTS 94:189-196

\section{Figures}

\section{A: Palmitic acid (16:0) B: Stearic acid (18:0) C: Oleic acid (18:1) D: Linoleic acid (18:2) E: Behenic acid (22:0)}

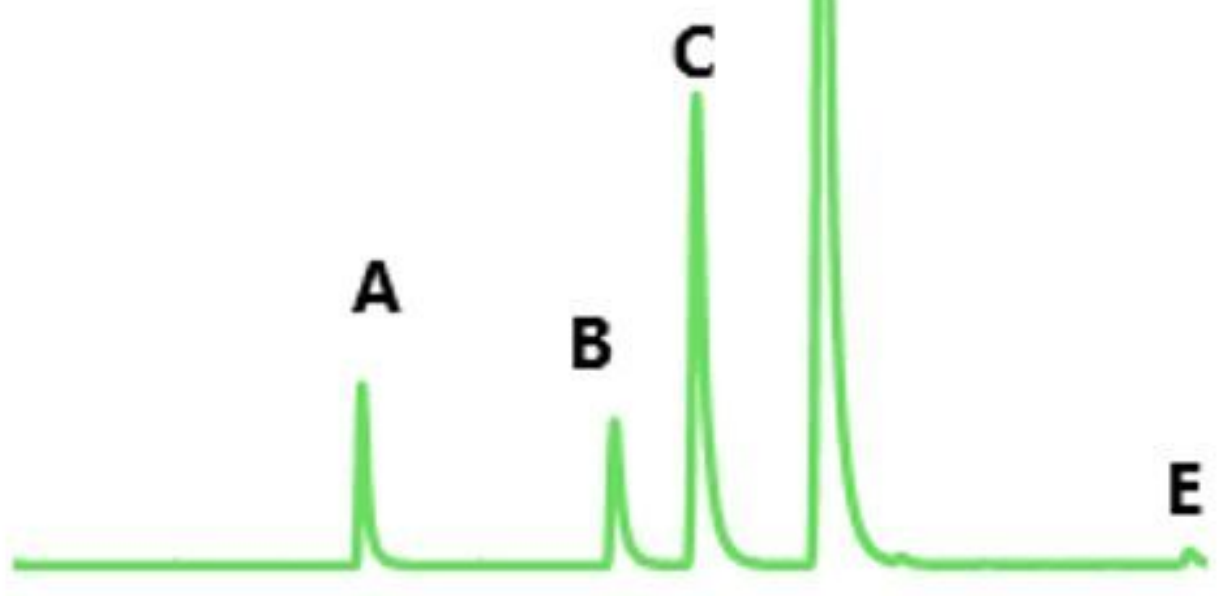

Figure 1

GC-MS sunflower oil chromatogram. 
D

A: Palmitic acid (16:0)

B: Stearic acid (18:0)

C: Oleic acid (18:1)

D: Linoleic acid (18:2)

E: Linolenic acid (18:3)

F: Behenic acid (22:0) C
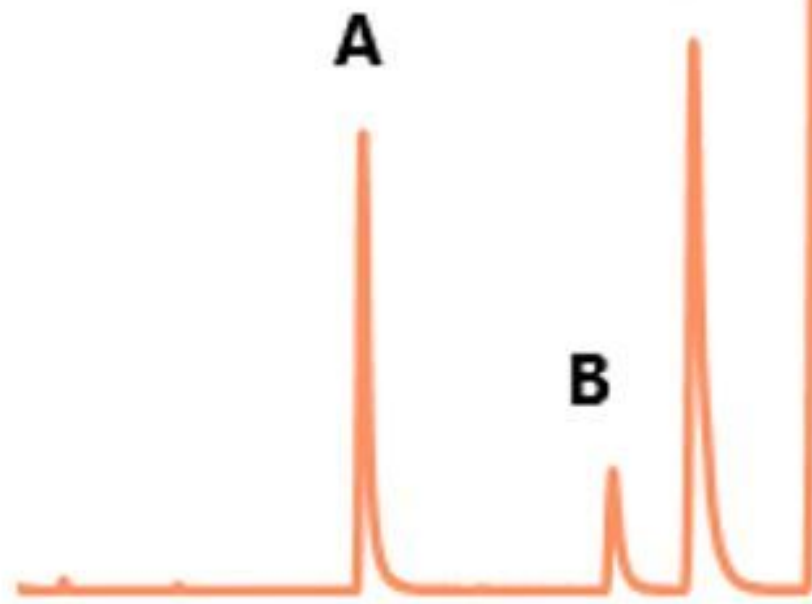

$\mathbf{E}$

Figure 2

GC-MS soybean oil chromatogram.

\section{Supplementary Files}

This is a list of supplementary files associated with this preprint. Click to download.

- graphicabstract.pptx 